\title{
Results of research of mental health of teenagers in conflict with the law in East Kazakhstan region
}

\author{
Svetlana Stelmakh ${ }^{1, *}$, Irina Matskevich ${ }^{1}$, Elena Barabanova $^{1}$ \\ ${ }^{1}$ NAS East-Kazakhstan University S. Amanzholov, Ust-Kamenogorsk, Kazakhstan
}

\begin{abstract}
The article systematizes the results of the study of adolescent health in conflict with the law in East Kazakhstan region. Adolescent mental health is considered a basic condition for development and well-being. It takes into account international practice of working with children in conflict with the law, which updates the needs of children for special work and special assistance. Mental health as a basic basis for assessment is given a significant place. In order to reduce the risks of repeated conflicts with the law and to plan recovery programs, it is necessary to understand the basis of well-being - the state of mental health of children. The study was conducted on a sample of 511 people using the methods MAYSI-2 and STAB. On the basis of the study, activities can be planned that will help adolescents to receive assistance in the field of mental health.
\end{abstract}

\section{Introduction}

The study used the understanding of mental health as "a state of well-being in which a person realizes his or her abilities, can withstand the usual stresses of life, can productively perform their activities, and can contribute to society" (WHO Constitution, 2015) [1].

However, the article used the concept and criteria of mental health, which are closer to the pole of psychiatric, clinical and psychological models of understanding. It is important for us to assess the likelihood measure, the propensity for the development of a mental disorder in children in conflict with the law in order to find the most adequate way to respond.

A study by Teplin, LA, Abram, KM, McClelland, GM, Dulcan, MK, \& Mericle, AA [23] recommends focusing on the following issues for a holistic understanding of the need to develop services for children in conflict with the law: using uniform diagnostic tools, accounting for girls and finding the specifics of their development, using large samples of respondents.

That is why the study focused on the use of previously identified criteria of mental "not normal": alcohol / drug use, high levels of aggression, signs of depression and anxiety, presence of somatic complaints, presence of suicidal ideas, and impaired thinking.

The category of children in conflict with the law is understood in the article as a category of children (from 12 to 18), which has a different degree of contact with the law in the form of a conflict, which has, as consequences for the child, various restrictions (from registration to special police register to probation). A child's conflict with the law can manifest itself both

\footnotetext{
*Corresponding author: stelmah_svetlana@mail.ru
} 
in the form of an offense, and in the form of committing so-called status crimes (running away from home, not going to school). The child's conflict with the law is a complex stage in impaired socialization. However, the practice of working with such children is most often in the zone of punishment, stigmatization as a reaction of society. The best practices (in accordance with the UN Riyard Recommendations) in order to restore socialization are recognized practices of assessing the needs of the child, including assessing impaired socialization and building an intervention in the best interests of the child.

Most mental disorders occur during childhood and adolescence. Very often, the trigger mechanisms are crisis and traumatic experiences, stresses. Studies of adolescent well-being in different countries (Innocenti) by Bianchera, Emanuela [2] $(2020,2019)$ show that depression in adolescents is widespread in all countries of the world. A joint study by the ME of Kazakhstan and UNICEF (2014-2016) [6], as part of the Global School-based Student Health Survey (GSHS) [3], confirms this thesis: $40-60 \%$ of children in conflict with the law have mental health problems.

Adolescence is specific (Elian Fink, PhD, Praveetha Patalay, $\mathrm{PhD}$, Helen Sharpe, PhD, Simone Holley, PhD, Jessica Deighton, PhD, and Miranda Wolpert, PsychD). [4] experiences of crisis and stress states, internal and social conflicts, conflicts with norms and rules (conflict with law), instability of emotional development. The Riyadh [5] recommendations on juvenile delinquency prevention suggest that children's mental health should be given priority when planning prevention interventions or interventions.

Studies from the U.S. and EU countries show that the vast majority of adolescents who break the law are boys (91\%) aged 16-17 (79\%). 40-80\% of juvenile inmates have at least one diagnosable mental health disorder. While the prevalence of mental health disorders among the general population is about $20 \%$. Approximately one in four adolescents in conflict with the law suffers from a serious mental illness that impairs their functioning [12].

Global studies on the prevalence of mental health problems among adolescents in conflict with the law in the United States, England, Australia, Russia, the Netherlands, Denmark, Canada, and Spain [9] demonstrate the specific distribution of problems (Table 1).

Table 1. Percentage distribution of mental health problems among adolescents in conflict with the law.

\begin{tabular}{|c|l|c|c|}
\hline$\#$ & \multicolumn{1}{|c|}{ Types of disorders } & Boys & Girls \\
\hline 1 & Behavioral disorder & $52.8 \%$ & $52.8 \%$ \\
\hline 2 & Attention Deficit Disorder and Hyperactivity Disorder & $11.7 \%$ & $29.2 \%$ \\
\hline 3 & Major depressive disorder & $10.6 \%$ & $18.5 \%$ \\
\hline 4 & Psychotic illness & $3.3 \%$ & $2.7 \%$ \\
\hline
\end{tabular}

Studies of the occurrence of PTSD in adolescents found that children in conflict with the law have such indicators 10-15 times higher: this is due to risks of abuse and psychological trauma. 30-61\% of juvenile offenders with a psychiatric disorder have a concomitant disorder associated with substance use $[10,11]$. However, only $20 \%$ of children in conflict with the law receive appropriate mental health care [10].

According to official statistics, in 2019, 2,824 criminal offenses were committed by minors in Kazakhstan (data from the Committee on Legal Statistics and Special Records of the General Prosecutor's Office).

\section{Methods}

The study was conducted in accordance with the Basic Plan of Operations of the Government of the Republic of Kazakhstan and the United Nations Children's Fund (UNICEF) for 20162020 to ensure better quality of diversion, probation, and rehabilitation schemes for children in the justice process. 
In accordance with the Plan's objectives to study the situation in the region with the highest rates of child crime, the study was conducted in the East Kazakhstan region.

The assessment tool included a number of scales for studying behavioral disorders, mood disorders, anxiety states and substance abuse, assessment of suicidal risks (behavior, cognitions), antisocial personality traits, impulsiveness, and aggressiveness [5].

The objectives of the study were: to identify children at risk of suicidal behavior and mental health problems among adolescents in conflict with the law; to refer adolescents in conflict with the law with mental health needs to appropriate treatment and intervention methods; and to collect epidemiological data on mental health of adolescents in conflict with the law.

All survey scales passed the system of direct and reverse translation into Russian and Kazakh languages. The procedures for standardizing the scales were not carried out, but the indicators of the norm reflected in the publications on the use of questionnaires were used.

The child survey system was based on the use of a battery of scales:

Massachusetts Youth Screening Tool-2 (MAYSI-2) T. Grisso and R. Barnum. It is a concise mental health screening tool for administrative admission procedures for any juvenile justice institution or service. completed in more detail using clinical and clinicalpsychological methods. For use in Russian conditions, the questionnaire is being adapted (studies by E.G. Dozortseva), but the results of the adaptation have not yet been published. The technique is a questionnaire completed by the teenager himself within 15 minutes. But in our study, the questionnaire was not given to the child to fill out, but a survey-interview of the child was conducted. The purpose of the questionnaire is to identify children who may require immediate attention regarding the possible risk of suicide and the emergence of needs in connection with mental health and substance use problems. The screening consists of 52 questions about behavior, thoughts or feelings, to which young people answer "yes" or "no" if the statement is true for them in the "past few months".

The system of interviewing children was based on the use of a battery of scales:

Massachusetts Youth Screening Tool-2 (MAYSI-2). It is a brief mental health screening tool for administrative procedures when entering any juvenile justice institution or service. The purpose is to identify children who may require immediate attention for possible suicide risk and needs related to mental health problems and substance use. The screening consists of 52 questions about behavior, thoughts, or feelings that young people answer "yes" or "no" if the statement is true for them in the "last few months.

The questionnaire includes scales: alcohol/drug use, anger - irritation, depression anxiety, somatic complaints, suicidal ideas, and impaired thinking (boys only).

MAYSI-2 subscales have two types of control levels: Warning: the number of points scored at a level that may have a "clinical significance", warning: an exceptionally high number of points requiring intervention, the subscales "Traumatic experiences", does not have a control level, because points indicate self-evaluation of the impact of events, not symptoms.

Anti-social Behavior Subtype Questionnaire (STAB). The STAB is a short, self-filled questionnaire that evaluates three types of anti-social behavior. Participants are asked to assess how often they engage in one of these types of behaviors: physical aggression: includes fighting, physical bullying, irritability, anger management problems and threats to others, social aggression: includes gossip, the spread of rumors, targeted attempts to destroy someone's reputation and hurt feelings by expressing negative feelings about their appearance, actions and beliefs, violation of the rules: includes theft, selling drugs, vandalism, suspension from school or work, garbage disposal, and others.

The 32 points in the survey were rated on a 5-point Likert scale from "never" to "almost always". 


\section{Results}

The sample included almost all children registered with the police in the East Kazakhstan region, except for 17 children who refused to take part in the survey. Due to the specifics of accounting, it was not possible to balance the sample by age. Sample characteristics by age: $69.7 \%$ of children aged $16-18 ; 17.2 \%$ - $14-15$ years old, $7.7 \%$ - $12-13$ years old and $6.4 \%$ children from 7 to 11 years old.

Sampling characteristics: 511 adolescents in conflict with the law (419 in Russian; 92 in Kazakh). Of these, $30 \%$ were girls and $70 \%$ were boys.

The specifics of the sample are presented taking into account the type of conflict with the law (conditionally sentenced children $2.9 \%$, convicted with the use of alternative measures of educational influence $7.8 \%$, exempted from criminal prosecution $42.6 \%$, homeless and street children $15.1 \%$, who committed status crimes $22.7 \%$ who committed administrative offenses $8.8 \%$ ).

Table 2. Children in conflict with law in East Kazakhstan region.

\begin{tabular}{|c|c|c|c|c|c|}
\hline $\begin{array}{c}\text { Convicts } \\
\text { on parole } \\
\text { e }\end{array}$ & $\begin{array}{c}\text { Convicts with } \\
\text { alternative } \\
\text { measures }\end{array}$ & $\begin{array}{c}\text { Exempt from } \\
\text { criminal } \\
\text { prosecution }\end{array}$ & $\begin{array}{c}\text { Street and } \\
\text { homeless } \\
\text { persons }\end{array}$ & $\begin{array}{c}\text { Statutory } \\
\text { offences }\end{array}$ & $\begin{array}{c}\text { Administrative } \\
\text { Offences }\end{array}$ \\
\hline 15 & 40 & 235 & 77 & 116 & 45 \\
\hline \multicolumn{6}{|l|}{ Total 528} \\
\hline \multicolumn{6}{|c|}{ Children who took part in the study } \\
\hline 15 & 40 & 218 & 77 & 116 & 45 \\
\hline \multicolumn{6}{|l|}{$\%$} \\
\hline 2.9 & 7.8 & 42.6 & 15.1 & 22.7 & 8.8 \\
\hline
\end{tabular}

The living conditions of adolescents were distributed as follows (Figure 1): most children live in single-parent families, more than one-third with both parents.

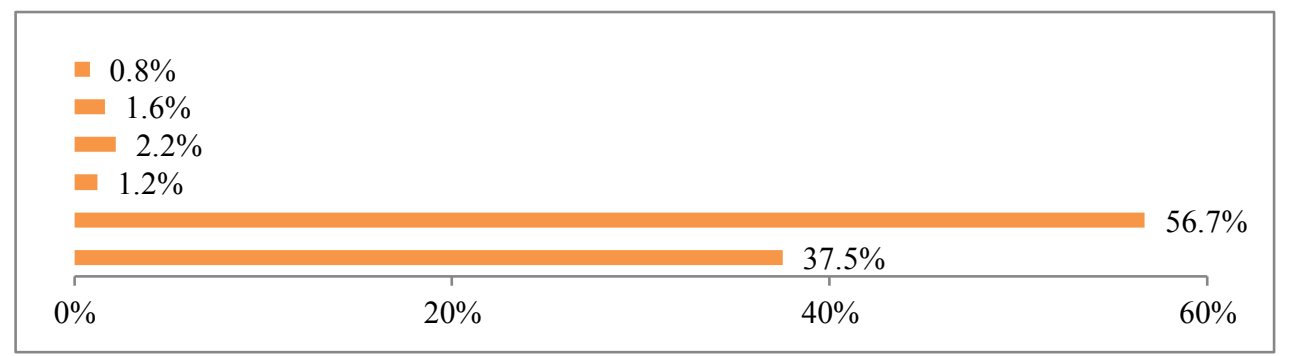

Fig. 1. Histogram of the percentage distribution of teenagers by living conditions $(56.7 \%$ with one parent, $37.5 \%$ with both parents, $2.2 \%$ with adoptive parents, $1.6 \%$ with shelter, $1.2 \%$ with relatives, and $0.8 \%$ with other people).

Analysis of sibling in the family revealed that $29 \%$ of children have two or more siblings, $35 \%$ have one sibling, and $26 \%$ do not have siblings.

Analysis of test subjects' education and employment levels revealed that $98.6 \%$ of the sample currently attend school, $1.2 \%$ are employed, and $0.2 \%$ are unemployed. $7 \%$ of the sample stayed in school at least once for the second year (Figure 2). 


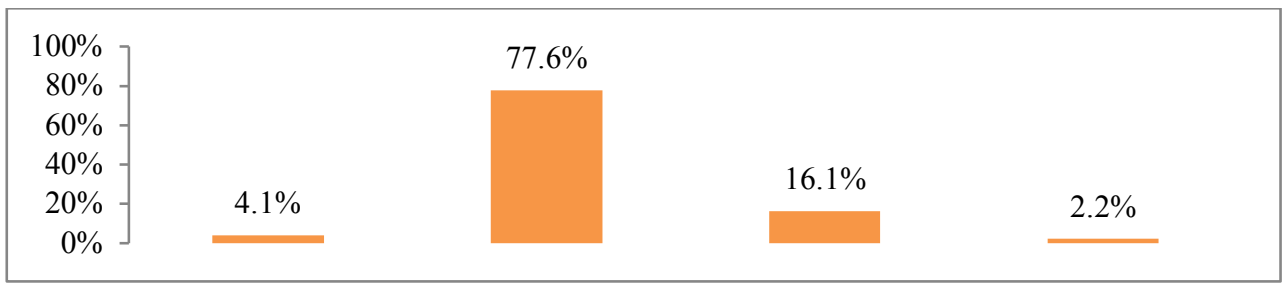

Fig. 2. Histogram of the percentage distribution of adolescents by education level.

Screening analysis showed the following results (Tables 3-8).

Table 3. Alcohol/narcotics use.

\begin{tabular}{|c|c|c|c|}
\hline $\begin{array}{c}\text { Boys } \\
\text { Average value } \pm \text { SD }\end{array}$ & $\begin{array}{c}\text { Girls } \\
\text { Average value } \pm \text { SD }\end{array}$ & $\begin{array}{c}\text { Total } \\
\text { Average value } \pm \text { SD }\end{array}$ & t-critterion \\
\hline $1.40 \pm 1.67$ & $0.99 \pm 1.57$ & $1.28 \pm 1.65$ & $\begin{array}{c}\text { The differences are } \\
\text { not significant }\end{array}$ \\
\hline
\end{tabular}

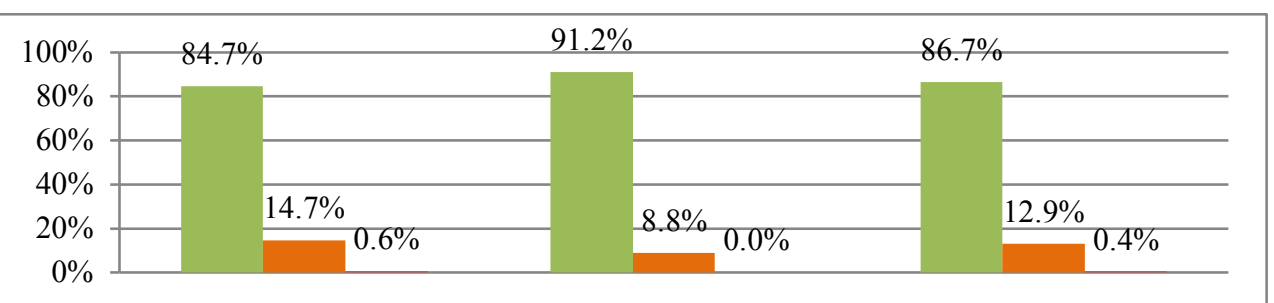

Fig. 3. Histogram of the percentage distribution of respondents by alcohol consumption (data group 1 - boys, group 2 - girls, group 3 - general data on the sample. Green color - norm, orange color warning, cherry color - warning).

Thus, the average values in the sample show that the majority of children have normalized indicators and, most likely, do not drink alcohol. However, $14.7 \%$ of boys and $8.8 \%$ of girls require precautionary action. $0.6 \%$ of boys require preventive action and urgent response.

For such children, an immediate response should be organized and included in programs of involvement in social activities, work with the family is necessary (in some cases, the treatment of parents and the socialization of disadvantaged families).

An analysis of the negative feelings children experience showed significant differences between girls and boys.

Table 4. Negative feelings: anger, irritation.

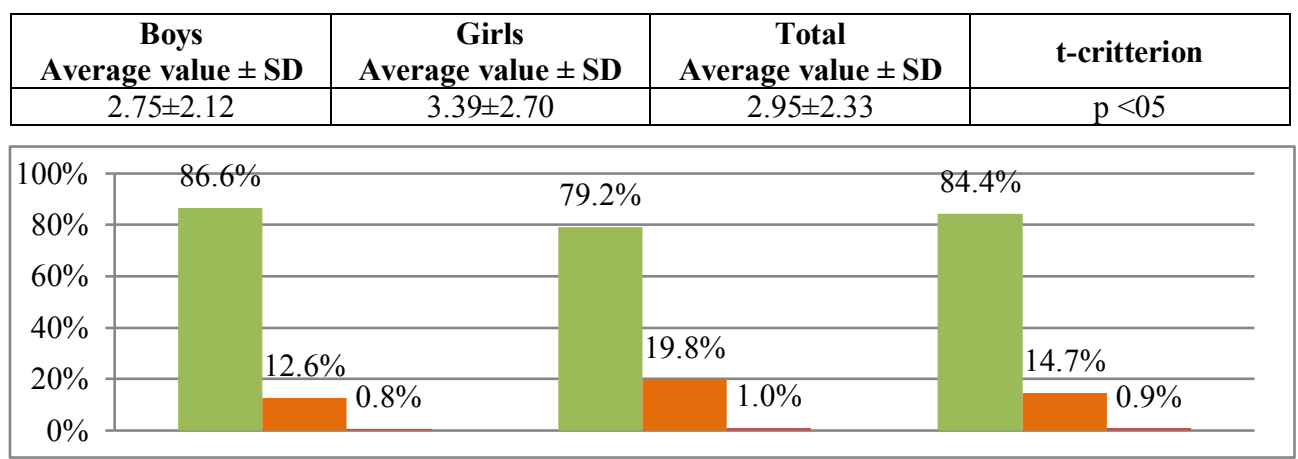

Fig. 4. Histogram of the percentage distribution of respondents with symptoms of anger, irritation (data group 1 - boys, group 2 - girls, group 3 - general data on the sample. Green color - normal, orange color - warning, cherry blossom - warning). 
Thus, the average values in the sample show that the majority of children have normalized indicators. However, $12.6 \%$ of boys and $19.8 \%$ of girls require preventive action. About $1 \%$ of children require preventive action and urgent response.

It is necessary to provide programs for working with negative feelings, groups for working out aggression, individual counseling sessions to find sources of negative emotions.

The next block of the questionnaire revealed feelings of depression and anxiety.

Table 5. Feelings of depression, anxiety.

\begin{tabular}{|c|c|c|c|}
\hline $\begin{array}{c}\text { Boys } \\
\text { Average value } \pm \text { SD }\end{array}$ & $\begin{array}{c}\text { Girls } \\
\text { Average value } \pm \text { SD }\end{array}$ & $\begin{array}{c}\text { Total } \\
\text { Average value } \pm \text { SD }\end{array}$ & t-critterion \\
\hline $1.77 \pm 1.83$ & $2.62 \pm 2.37$ & $2.04 \pm 2.05$ & $\mathrm{p}<001$ \\
\hline
\end{tabular}

\begin{tabular}{|l|l|l|l|}
\hline $80 \%$ & $73.0 \%$ & & \\
\\
\cline { 2 - 4 }
\end{tabular}

Fig. 5. Histogram of the percentage distribution of respondents by symptoms of depression, anxiety (data group 1 - boys, group 2 - girls, group 3 - general data on the sample. Green color - norm, orange color - warning, cherry color - warning).

Thus, the average values in the sample show that the majority of children have normalized indicators. However, many children require precautionary actions, $23.7 \%$ of boys and $30.5 \%$ of girls. $3.3 \%$ of boys and $10.5 \%$ of girls require preventive action and urgent response.

These indicators require the development of programs to reduce depression and anxiety, search for sources of depression and anxiety. It is noted that children who are registered in the category of committing status offenses are all included in the group in need of preventive action and response. It is likely that accounting and accounting requirements can be the source of depression and anxiety.

The next block revealed somatic complaints.

Table 6. Somatic complaints.

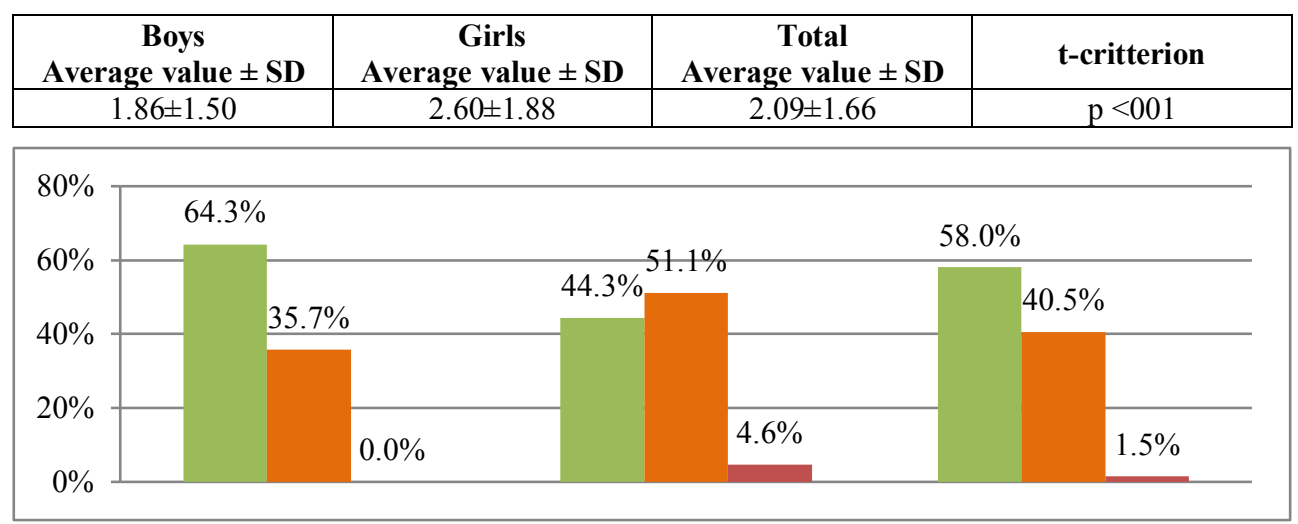

Fig. 6. Histogram of the percentage distribution of respondents by symptoms of somatic disorders (data group 1 - boys, group 2 - girls, group 3 - general data on the sample. Green color - norm, orange color - warning, cherry color - warning). 
Thus, the average values in the sample show that the majority of boys have normalized indicators, but more than half of the girls $(51.1 \%)$ have symptoms of somatic disorders, which require preventive action. Immediate preventive action for symptoms of somatic disorders is needed for $4.6 \%$ of girls.

Thus, the mean values in the sample show that the majority of boys have normalized indicators, but more than half of girls $(51.1 \%)$ have symptoms of somatic disorders, and more than a third of boys $(35.7 \%)$, which require preventive action. Immediate preventive action for symptoms of somatic disorders is needed for $4.6 \%$ of girls.

It is likely that low medical activity and social neglect limit access to medical care for children in conflict with the law. Social and medical intervention and the organization of a comprehensive medical examination are required.

Quite a big problem was revealed by the block of the survey on possible suicidal thoughts.

Table 7. Suicidal thoughts.

\begin{tabular}{|c|c|c|c|}
\hline $\begin{array}{c}\text { Boys } \\
\text { Average value } \pm \text { SD }\end{array}$ & $\begin{array}{c}\text { Girls } \\
\text { Average value } \pm \text { SD }\end{array}$ & $\begin{array}{c}\text { Total } \\
\text { Average value } \pm \text { SD }\end{array}$ & t-critterion \\
\hline $0.44 \pm 0.87$ & $1.10 \pm 1.59$ & $0.65 \pm 1.18$ & $\mathrm{p}<.001$ \\
\hline
\end{tabular}

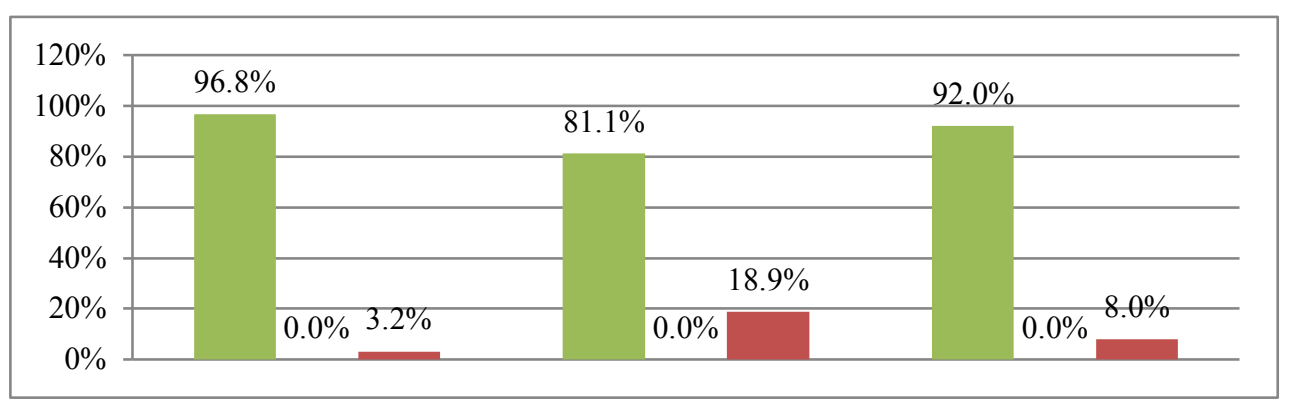

Fig. 7. Histogram of the percentage distribution of respondents by the presence of suicidal ideation (data group 1 - boys, group 2 - girls, group 3 - general data on the sample. Green color - norm, orange color - warning, cherry color - warning).

Thus, the sample means show that the majority of children have normalized indicators and, most likely, do not have suicidal thoughts. However, $3.2 \%$ of boys and $18.9 \%$ of girls require preventive action and urgent response. These are significant numbers (every fifth girl in conflict with the law has suicidal thoughts).

Therefore, in order to work with children in conflict with the law, it is mandatory to screen for suicidal risks and work programs for both depressive states and suicidal thoughts (as a measure of response and redirecting negative experiences into positive opportunities).

Consider the results of the wrongful behavior questionnaire.

Table 8. Results according to the STAB questionnaire.

\begin{tabular}{|l|l|l|l|l|}
\hline \multicolumn{1}{|c|}{ Types of behavior } & $\begin{array}{c}\text { Boys } \\
\text { Average value } \pm \\
\text { SD }\end{array}$ & $\begin{array}{c}\text { Girls } \\
\text { Average value } \\
\pm \text { SD }\end{array}$ & $\begin{array}{c}\text { Total } \\
\text { Average } \\
\text { value } \pm \text { SD }\end{array}$ & t-critterion \\
\hline Physical aggression & $19.58 \pm 6.94$ & $17.73 \pm 6.53$ & $19.01 \pm 6.87$ & $\mathrm{p}<.001$ \\
\hline Social aggression & $15.8 \pm 5.40$ & $15.22 \pm 4.06$ & $15.61 \pm 4.67$ & not significant \\
\hline Breaking the rules & $14.12 \pm 3.91$ & $14.47 \pm 3.13$ & $14.23 \pm 3.68$ & not significant \\
\hline Total & $49.59 \pm 13.49$ & $47.44 \pm 11.18$ & $48.92 \pm 12.84$ & not significant \\
\hline
\end{tabular}

The results of self-assessment of behavior of adolescents show an increased level of physical aggression, a normalized level of social aggression and violation of rules, but with a wide spread of data upward. 
In combination with the data on the screening questionnaire, it is possible to single out the accumulation of physical aggression in adolescents, which can be a source of conflict with the law, and in some adolescents, social aggression as a rejection of social injustice and the desire to violate the rules as a protest form of behavior.

\section{Discussion}

Primary processing of the results without looking for correlations shows that adolescents in conflict with the law in Kazakhstan are at risk of developing mental health problems.

The findings are consistent with global statistics showing that approximately $60-70 \%$ of adolescents in conflict with the law have a mental disorder.

Somatic complaints (42\%) accompanied by anxiety-depressive symptoms $(30 \%)$ are the most common mental health problems in this sample.

Suicidal thoughts were revealed in $8 \%$ of children (girls). Data on possible risk were transferred to educational institutions for building preventive programs.

Girls are at greater risk of mental health problems than boys.

Boys confessed to physical aggression in behavior more often than girls.

With these results in mind, Kazakhstan needs to develop appropriate treatment and intervention strategies to meet the mental health needs of adolescents in conflict with the law. Strategies for promoting the mental health of juveniles involved in the justice system need to be holistic, develop social skills, change behavior and involve families in intervention plans. Strategies for early detection, assessment, referral and treatment of mental health problems are a key component of promoting the mental health of juvenile offenders and should specifically focus on the presence of co-occurring drug use / abuse.

This requires access to education, social protection and mental health services. Without appropriate intervention, children are at risk of reoffending.

Further research can be carried out in several directions. The first of them can be aimed at studying family situations and finding correlations in this direction. The second direction of research can be aimed at modeling the content of legal, social support, psychological intervention and strategies for mental health care. The third direction of research can be deployed towards research methodology and supplemented by in-depth interviews.

\section{References}

1. WHO Charter, https://www.who.int/ru/news-room/fact-sheets/detail/mental-healthstrengthening-our-response

2. E. Bianchera, Innocenti Research Digest on Adolescence 16 (Miscellanea UNICEF Office of Research - Innocenti, Florence, 2020) https://www.unicefirc.org/publications/1046-innocenti-research-digest-on-adolescence-14.html

3. Global school-based student health survey (GSHS), https://www.cdc.gov/GSHS/

4. E. Fink, P. Patalay, H. Sharpe, S. Holley, J. Deighton, M. Wolpert, Journal of Adolescent Health 56, 502-507 (2015) DOI: https://doi.org/10.1016/j.jadohealth.2015.01.023

5. E.I. Barabanova, E.V. Dergacheva, I.K. Matskevich, S.A. Stelmakh, Bulletin of KazNU named after Al-farabi. Psychology and Sociology Series 1(64), 13-25 (2018)

6. Committee on legal statistics and special records of the General Prosecutor's Office of the Republic of Kazakhstan, http://pravstat.prokuror.gov.kz/rus/o-kpsisu/deyatelnostkomiteta/analiticheskaya-informaciya 
7. K.M. Abram, J.J. Washburn, L.A. Teplin, K.M. Emanuel, E.G. Romero, G.M. McClelland, Psychiatric Services 58(10), 1311-1316 (2007) DOI: 10.1176/ps.2007.58.10.1311

8. W.E. Copeland, G. Keeler, A. Angold, E.J. Costello, Arch Gen Psychiatry 64(5), 577584 (2007) DOI: 10.1001 / archpsyc.64.5.577

9. S. Fazel, H. Doll, N. Långstrom, J Am Acad Child Adolesc Psychiatry 47(9), 1010-9 (2008) DOI: 10.1097 / CHI.ObO13e31817eecf3.

10. H. Steiner, I.G. Garcia, Z. Matthews, Journal of the American Academy of Child \& Adolescent Psychiatry 36, 357-365 (1997) DOI: 10.1097/00004583-199703000-00014

11. L.A. Teplin, K.M. Abram, J.J. Washburn, et al, OJJDP Juvenile Just Bull 13, 1-16 (2013)

12. G. Wasserman, L. McReynolds, C. Lucas, P. Fisher, L. Santos, Journal of the American Academy of Child and Adolescent Psychiatry 41, 314-321 (2002) DOI: 10.1097 / 00004583-200203000-00011

13. L. Villardón-Gallego, R. García-Carrión, L. Yáñez-Marquina, A. Estévez, Sustainability 10, 2138 (2018) doi: 10.3390 / su10072138

14. Vygotsky, L. S. (1978). Mind in Society: The Development of Higher Mental Process. Cambridge, MA: Harvard University Press.

15. M.D. Weist, M. Murray, Adv. School Mental Health Promotion 1, 2-12 (2008) doi: 10.1080 / 1754730X.2008.9715740

16. Promoting Mental Health: Concepts, Emerging Evidence, Practice: Summary Report (World Health Organization, Geneva, 2004) http://www.who.int/mental_health/evidence/en/promoting_mhh.pdf

17. Child and Adolescent Mental Health (WHO. World Health Organization, 2016) http://www.who.int/mental_health/maternal-child/child_adolescent/en/

18. Depression: Let's Talk" Says WHO, as Depression Tops List of Causes of Ill Health (WHO. World Health Organization, 2017) http://www.who.int/mediacentre/news/releases/2017/world-health-day/en/

19. J.A. Chiles, M.L. Miller, G.B. Cox, Depression Among Adolescent Offenders, PMID: 7425803, DOI: $10.1001 /$ archpsyc. 1980.01780230097015

20. T.P. Ulzen, D.C. Psych, H. Hamilton, The Canadian Journal of Psychiatry 43(1), 57-63 (1998) DOI: 10.1177 / 070674379804300106

21. L. Teplin, K. Abram, G. McClelland, A. Mericle, M. Dulcan, J. Washburn, S. Butt, The Mental Health Needs of Young Offenders: Forging Paths toward Reintegration and Rehabilitation (Cambridge University Press, Cambridge, 2007) DOI: 10.1017 / CBO9780511543913.003

22. T. Grisso, S. Fusco, M. Paiva-Salisbury, R. Perrault, V. Williams, R. Barnum, The Massachusetts Youth Screening Instrument-Version 2 (MAYSI-2): Comprehensive Research Review https://www.researchgate.net/publication/299346563_The_Massachusetts_Youth_Scre ening_Instrument-Version_2_MAYSI-2_Comprehensive_Research_Review 